\title{
Política macroprudencial, estabilidade financeira e pleno emprego: a contribuição de Minsky*
}

\author{
Mateus Coelho Ferreira ${ }^{\dagger}$
}

\begin{abstract}
Resumo
O objetivo deste trabalho é fazer uma discussão crítica da política macroprudencial no debate macroeconômico sob a perspectiva pós-Keynesiana. Parte-se da evidência que os instrumentos e definição desta política têm como referência teórica os pressupostos da macroeconomia ortodoxa. Todavia, de uma perspectiva pós-Keynesiana, as causas para instabilidade financeira apresentam pressupostos diferentes. Neste ponto de vista, a instabilidade financeira assume um caráter essencialmente endógeno. Portanto, a política macroprudencial poderia não atingir o objetivo desejado, principalmente, porque uma dessas limitações reside no fato do sistema bancário criar constantemente inovações financeiras. Logo, é preciso estabelecer uma proposta alternativa que vá além da necessidade de implementar regulações bancárias. Seguindo Minsky e outros autores pós-Keynesianos, uma solução para minimizar as crises econômicas seria adotar a premissa de que para a estabilização de economias capitalistas modernas é necessário o compromisso da política econômica com a obtenção do pleno emprego.
\end{abstract}

Palavras-chave: Política macroprudencial, estabilidade financeira, teoria pós-Keynesiana

\begin{abstract}
The objective of this paper is to make a critical discussion about the macroprudential policy in the macroeconomic debate under a post-Keynesian perspective. It is evident that the instruments and definition of this policy have as theoretical reference presumptions of orthodox macroeconomics. However, from a post-Keynesian perspective, the causes for financial instability present different assumptions. From this point of view, financial instability takes on an essentially endogenous character. Therefore, the macroprudential policy might not achieve the desired goal, especially, because one of these limitations lies in the fact that the banking system constantly creates financial innovations. Moreover, it is necessary to establish an alternative proposal that goes beyond the need to implement banking regulations. Following Minsky and other post-Keynesian authors, a solution to minimize economic crises would be to adopt the premise that for stabilization of modern capitalist economies is necessary the commitment of economic policy to obtain full employment.
\end{abstract}

Keywords: macroprudential policy, financial stability, Post-Keynesian theory

JEL Classification: G28; E12; E32; E61.

\footnotetext{
O autor agradece aos comentários de Carmem Feijó e dos pareceristas anônimos. Uma versão preliminar foi apresentada no XII Encontro Internacional da AKB. Este trabalho teve apoio financeiro da CAPES (Coordenação de Aperfeiçoamento de Pessoal de Ensino Superior).

${ }^{+}$Universidade Federal do Rio de Janeiro, e-mail: mateuscf25@hotmail.com
} 


\section{Introdução}

O episódio da crise financeira de 2008 (crise do crédito subprime), nos Estados Unidos já se tornou um capítulo inesquecível na história da economia mundial. Podese afirmar que seu estopim esteve conectado ao crescimento do mercado imobiliário e seu financiamento por meio do sistema de hipotecas com a exposição do sistema financeiro ao instrumento de derivativos, especificamente, o Credit Default Swap (CDS). Por causa da sua relevância histórica para dinâmica da economia global, essa crise econômica gerou pelo menos dois grandes questionamentos internos no âmbito do estudo da macroeconomia: a) em determinar quais políticas macroeconômicas do chamado "Novo Consenso Macroeconômico" teriam favorecido o surgimento desta crise; b) qual foi a contribuição da desregulamentação do sistema financeiro neste processo. A partir deste momento, apareceram diversos questionamentos sobre os avanços e falhas acerca da teoria macroeconômica convencional e que buscaram determinar quais foram as políticas econômicas implementadas pelos governos que teriam favorecidos o surgimento dessa nova crise financeira global (Arestis, 2009; Blanchard et al., 2010; Blanchard e Summers, 2017; Romer, 2016).

Nesta perspectiva, Blanchard et al. (2010) evidenciaram que apesar de a política monetária por meio do uso da taxa de juros ter sido um instrumento importante para o controle da dinâmica inflacionária, seus resultados não demonstraram ser eficientes para conter a excessiva tomada de riscos por parte do sistema financeiro que levou a crise de 2008. Neste caso, seria preciso um novo cenário para operação da política econômica pelos países no mundo, presenciando uma maior sintonia entre a política monetária e a política de regulação financeira, sendo que essa última deveria partir para um ponto de vista mais macroeconômico.

Stiglitz (2010) aponta, por sua vez, que também a crise de 2008 ficou caracterizada pela existência de incentivos equivocados que direcionaram a decisão do sistema bancário para uma tomada excessiva de risco por meio do processo de securitização crescente de ativos. Este processo teve sua origem no aumento da desintermediação financeira permitido pela desregulamentação bancária. Essa situação, portanto, gerou uma reflexão importante para a teoria econômica, pois: "[...] these perverse incentives were a failure in modeling: a failure to understand the economics of securitization and the nature of systemic risk, and to correctly estimate small probability events"(Stiglitz, 2010, p. 21). Em outras palavras, existia uma baixa capacidade dos modelos tradicionais, até então, de compreender a dimensão e a natureza do chamado risco sistêmico em um ambiente financeiro pouco regulado.

Com base nesta premissa que a desregulação bancária foi um fator 
determinante para o início da crise financeira de 2008, a regulação voltou a cena nos debates entre os bancos centrais e organismos internacionais, sendo discutidos em diversos fóruns de âmbito mundial como o G20 - o grupo formado pelos representantes das finanças dos 19 países mais ricos do mundo e da Europa. Deste modo, um novo acordo de regulação bancária de âmbito internacional foi definido nestas rodadas de reuniões do G20: o acordo de Basileia III. Esse acordo introduziu novas bases regulatórias para diminuição do chamado risco sistêmico, por meio do fortalecimento das instituições financeiras. $\bigcirc$ acordo criou novos mecanismos de monitoramento sobre os níveis de adequação para o capital e liquidez do sistema bancário. Isso se deve a uma ampliação dos elementos para medir a qualidade e conservação do capital principal, do controle sobre fluxos de derivativos financeiros e limite da alavancagem do sistema financeiro, além de criar padrões internacionais para o cálculo da regulação sobre a liquidez bancária (LCR e NSFR). Tendo como diferencial em relação ao acordo anterior, a existência de suportes para implementação da política macroprudencial (BCBS, 2010).

Assim, a política macroprudencial surge tendo como finalidade aumentar a resiliência e a estabilidade do sistema financeiro, com o seu foco na análise em sua totalidade e contra os diversos choques adversos provenientes da elevação do chamado risco sistêmico, atuando sobre duas dimensões: temporal (como esse risco se acumula no tempo) e transversal (da interconexão entre as instituições individuais dentro das negociações nos mercado financeiros nacionais e internacionais). Portanto, seu objetivo é gerar um sistema mais robusto à choques adversos e reduzir a amplitude do ciclo financeiro (Oliveira et al., 2018). Consequentemente, são estabelecidos instrumentos de política que atuam sobre essas dimensões do risco sistêmico, de acordo com os diferentes riscos encontrados no sistema financeiro de cada país.

Apesar de existirem certos consensos em torno das suas definições, escopo e objetivos da política macroprudencial, tem-se um longo caminho a ser percorrido na definição de um ambiente para sua operacionalização ideal. Assim, devemos antes de qualquer conjuntura, definir as causas para instabilidade financeira e o papel do sistema financeiro e a sua devida relação (e consequências) com o ciclo econômico, para que dessa maneira, possam ser implementadas políticas ditas macroprudenciais que sejam efetivas. Para a teoria macroeconômica convencional existem duas fontes para instabilidade financeira: estariam na existência de falhas de mercado, isto é, causados por problemas de informação assimétrica como o risco moral e seleção adversa ou por causa de impactos provenientes de choques exógenos como uma 
corrida bancária ${ }^{1}$. Por outro lado, de acordo com a perspectiva pós-Keynesiana, as causas que afetam a instabilidade financeira e a acumulação do risco sistêmico no tempo possuem essências diferentes. Nesta perspectiva, o funcionamento de uma economia de mercado seria inerentemente estável, no qual a construção de uma crise é gerada de maneira essencialmente endógena via aumento da fragilidade do sistema financeiro (Minsky, 1982, 1986[2008], 1992). Consequentemente, a discussão sobre os objetivos da política macroprudencial poderia tomar uma nova direção em torno de um outro rumo institucional, indo além do papel da regulação bancária, dado que a estabilidade financeira não pode ser garantida, mas sendo apenas possível suavizar os impactos decorrentes de uma crise financeira por meio da implementação de "pisos e tetos" sobre a flutuação do ciclo econômico (Minsky, 1986[2008]). Portanto, discutir a questão da política macroprudencial e sua relação com a estabilidade financeira tem um caráter de propor alternativas para definir um ambiente para promoção de um sistema bancário sólido no longo prazo, capaz de absorver choques significativos de liquidez. Ademais, segundo Oliveira et al. (2018), o debate no sentido dos objetivos da política macroprudencial não é considerado novo na literatura pós-Keynesiana, especialmente, nos trabalhos de Hyman P. Minsky.

Em suma, este artigo tem como objetivo propor uma discussão crítica tendo a teoria pós-Keynesiana como referencial acerca da regulação bancária dita macroprudencial, principalmente, em relação às suas bases teóricas adotadas - a teoria macroeconômica convencional - que definem a concepção dos seus instrumentos de política ${ }^{2}$. Em particular, demonstra-se que ao adotar a visão convencional, pelo menos, do ponto de vista pós-Keynesiano, esta política poderá não ser o suficiente para atingir seus objetivos propostos, ou seja, suavizar o ciclo financeiro e impedir a ocorrência de novas crises financeiras. Em especial, devido ao caráter inovativo do sistema financeiro que cria mudanças radicais na forma de gerenciamento do seu balanço patrimonial, permitindo burlar as regulações instituídas e, portanto, criando novos mecanismos capazes de aumentar novamente a fragilidade financeira. Logo, a conclusão seria que é preciso adotar políticas econômicas alternativas para garantir a estabilidade financeira no longo prazo. Neste caso, a proposta sugerida, seguindo Minsky (e outros autores pós-Keynesianos), seria uma implementação de políticas contracíclicas denominadas de Big Government, Big

\footnotetext{
${ }^{1}$ Neste trabalho, a teoria macroeconômica ortodoxa (ou convencional) pode ser entendida como um consenso teórico existente entre acadêmicos e bancos centrais com respeito aos pressupostos e o modo de condução da política monetária, denominado "Novo Consenso Macroeconômico". Com relação aos seus pressupostos (e críticas), ver Arestis (2009).

${ }^{2}$ Apesar de relevante para discussão, este trabalho não busca construir uma crítica especificamente em tornos da metodologia e eficácia dos instrumentos de política macroprudencial. Para um resumo dos instrumentos adotados no mundo, ver Banco da Inglaterra (2011).
} 
Bank (Lender of last Resort) e Big Employment (Employer of last Resort). Nesta perspectiva, a estabilidade financeira dependerá da introdução desse conjunto de políticas econômicas com o compromisso da sustentação do nível de renda ao pleno emprego da economia.

Além desta introdução, a discussão está estruturada da seguinte maneira: na segunda seção, será realizado uma breve revisão sobre a definição e objetivos da política da política macroprudencial em relação a estabilidade financeira. Com relação a terceira seção, discute-se o papel do sistema bancário e as causas para instabilidade financeira na teoria convencional. Na quarta seção, faz-se um contraponto teórico sobre o debate levantado na seção anterior, conforme os aspectos da perspectiva pós-Keynesiana. A quinta seção discute uma proposta de política alternativa de estabilidade financeira baseada nesta mesma visão teórica, evidenciando a contribuição originalmente dada por Minsky. Por último, as considerações finais.

\section{A política macroprudencial: definição e objetivos em relação a estabilidade financeira}

Clement (2010), em uma análise sobre as origens da política macroprudencial, afirma que apesar de surgir recentemente como uma discussão mais relevante, o termo "macroprudencial" provém de um relatório do Bank for International Settlements (BIS) no ano de 1979. Nesta época, o BIS se preocupava com o aumento dos fluxos de capitais internacionais que seguiu entre as décadas de 70 e 80, principalmente, para os países subdesenvolvidos. Sua opinião era que estes fluxos significativos poderiam gerar desequilíbrios nas suas balanças de pagamentos, tornando-se um problema para a economia mundial no futuro. De fato, esta avaliação acabou demonstrando ser acertada em face do início das crises das dívidas externas em países da América Latina, a partir dos anos 80. Posteriormente a este relatório do BIS, foi introduzida a primeira citação ao termo em âmbito público, em 1986. Sua finalidade era relatar uma crescente preocupação com a expansão do mercado de securitização e opções de derivativos. Em especial, o relatório tinha um enfoque nos impactos e vulnerabilidades criadas por essas inovações financeiras (Clement, 2010, p. 4).

Com a crise financeira de 2008 e a introdução do Acordo de Basileia III, a política macroprudencial começou a se tornar um tema cada vez mais relevante para os organismos internacionais e para os bancos centrais de todo mundo, ou seja, acabando por se tornar o assunto da moda (Clement, 2010, p. 1). Segundo Clement (2010, p.1), "uma rápida pesquisa na internet revela que, desde janeiro de 2008, 
houve aproximadamente 123.000 referências para o termo, ao contrário, entre 2000 e 2007, houve apenas 5.000 indicações". Este cenário aponta para uma importância recente para o tema da política macroprudencial, que vem ganhando espaços crescentes na literatura. ${ }^{3}$ Assim, no debate da regulação bancária atual, a política macroprudencial surge com o objetivo de garantir a estabilidade do sistema financeiro em sua totalidade, impedindo os efeitos adversos advindos da acumulação do risco sistêmico (Galati e Moessner, 2011). Pode-se definir esse tipo de risco como aquele que leva uma interrupção generalizada da oferta de serviços financeiros que cause danos ao sistema bancário e que gere, como sua consequência, efeitos negativos sobre a economia real (FMI, 2016, p. 4). Portanto, a política macroprudencial também estaria relacionada com a questão Too Big to Fail, isto é, em que a falência de uma grande instituição financeira teria efeitos potenciais de contágio negativos que impactam o restante da economia.

Lee et al. (2017) afirmam que o objetivo principal da política macroprudencial seria de prevenir a formação do risco sistêmico no sistema financeiro, incluindo seus efeitos potenciais sobre a economia real e fluxos internacionais de capitais. Nesta perspectiva, o escopo de atuação da política macroprudencial deve abranger todas as fontes possíveis de criação de risco sistêmico (FMI, 2011)4.

Bastos (2010, p. 82), por sua vez, afirma que a política macroprudencial pretende "contribuir para reduzir a amplitude do ciclo financeiro, procurando evitar a alavancagem excessiva na fase ascendente e minimizar os efeitos recessivos na fase descendente". Por outro lado, o Banco da Inglaterra (2009) apresenta um outro entendimento possível em relação aos objetivos da política macroprudencial: o foco deveria ser apenas em manter o nível da oferta de crédito e da intermediação de serviços financeiros de forma estável para economia ${ }^{5}$.

Especificamente, de acordo com Borio (2003, p. 2): "the objective of macroprudential approach is to limit the risk of episodes of financial distress with significant losses in terms of the real output for the economy as a whole". Neste caso, pode-se definir um episódio de estresse financeiro como um choque adverso que

\footnotetext{
3 Por exemplo, ver Avdjiev et al. (2016) e Carvalho e Castro (2015).

${ }^{4}$ Por outro lado, por ter um caráter preventivo, o foco da política macroprudencial não recai sobre as consequências que foram geradas por essa acumulação do risco sistêmico. Neste caso, a resposta deve ser dada por outras políticas econômicas como a monetária e a fiscal.

${ }_{5}^{5}$ Porém, perseguir esse objetivo teria como resultado prático, implicitamente, o mesmo de aumentar a solidez do sistema financeiro em relação aos efeitos provocados pelo ciclo econômico. Porque dado que a finalidade principal do sistema bancário é promover empréstimos e financiamentos (seja de curto ou longo prazo), isso significa que estabilizar o nível de crédito ofertado corresponderia também em manter seus índices de lucratividade e liquidez, portanto, sua capacidade de absorver choques adversos no tempo.
} 
provoque uma queda acelerada na rentabilidade do sistema no curto prazo, assim, permitindo que uma dada instituição individual incorra em prejuízos significativos, ou seja, gerando uma alta probabilidade de que esta não consiga suportar o pagamento de juros de sua dívida no curto prazo, entrando em um processo de crise de liquidez ou solvência (Kindeblerger e Aliber, 1978 [2005], p. 94).

Esta visão de supervisão bancária admite modelos de análise do risco sistêmico que envolvem um lado endógeno, porque se subentende que em períodos de formação de bolhas de ativos na economia, os bancos adotam um comportamento de reforçar a tendência altista dos preços dos ativos, adquirindo um

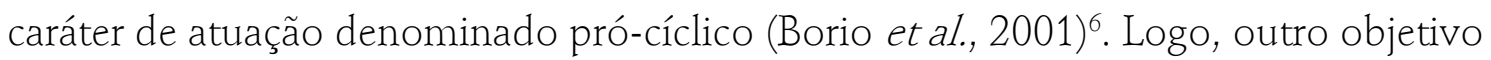
da política macroprudencial é atuar de forma preventiva sobre as possíveis variáveis formadoras do risco sistêmico dentro do sistema financeiro, em especial, aquelas decorrentes do próprio funcionamento do sistema, tal como surtos de expansão do nível de crédito que sejam incompatíveis com o ritmo de crescimento da atividade econômica. Porém, se não for o caso, a política macroprudencial poderá se demonstrar ineficiente ${ }^{7}$.

Em resumo, a política macroprudencial se apresenta como um suporte para prevenção (e diminuição) das ocorrências de crises sistêmicas que impactam a economia real, pois, "[...Jfinancials crises are not an act of God or perfect storms, they are the outcome of systemic distortions in perceptions of risk and responses to it, including as result of fallacies of composition" (Borio, 2010, p. 2). Caso necessário, a implementação dos instrumentos de política macroprudencial poderá ser coordenado conjuntamente com a política microprudencial, monetária e fiscal, mas desde que, estes tenham como princípios a obtenção da estabilidade do sistema financeiro (ver FMI, 2011)

De todo modo, ao delinear políticas de estabilização financeira, é preciso ter em mente que "[...] the design of the effective macroprudential policy tool requires a solid understanding of the linkages between financial sector and the real economy" (FMI, 2011, p. 18). Isso significa que também é preciso definir quais são as possíveis

\footnotetext{
6 Pode-se definir prociclicidade como um tipo de comportamento de um determinado setor da economia que possui uma correlação positiva entre o nível de sua atividade produtiva e o ciclo econômico, isto é, se o ciclo é ascendente (importando aumentos de produto e renda), este setor passa a aumentar seu nível de oferta para acompanhar o ritmo de crescimento da demanda, portanto, ampliando a tendência esperada do ciclo.

7 O Banco da Inglaterra (2009) aponta, por exemplo, o caso da Bolha da Internet nos Estados Unidos que aconteceu entre os anos de 1999-2000.

${ }^{8}$ A política microprudencial se refere à proteção da solidez financeira de cada instituição de forma individual. Nas palavras de Borio (2003, p.) "a micropudentialist would argue that a financial system to be sound it is necessary and sufficient that each institution is sound".
} 
fontes para instabilidade no sistema financeiro para que se possam ser implementadas políticas ditas macroprudenciais que sejam realmente efetivas. Em outras palavras, a escolha dos instrumentos, estruturas e modelos de governança de política macroprudencial dependerá da visão teórica envolvida em seu processo de formulação. Neste sentido, a teoria macroeconômica convencional vem se constituindo como uma das principais fontes teóricas para a definição da concepção da política macroprudencial ${ }^{9}$.

Como será exposto na seção seguinte, esta teoria parte do pressuposto que os bancos são considerados como meros intermediários financeiros, ou seja, adotam um comportamento passivo na economia. Ainda, nesta visão teórica são apontadas como fontes para as causas de crises financeiras impactos provenientes de choques adversos exógenos ou porque existiriam problemas informacionais que promovem equilíbrios ineficientes na presença das chamadas falhas de mercado ${ }^{10}$. Esta teoria, posteriormente, será contestada pela perspectiva teórica pós-Keynesiana.

\section{O papel dos bancos e as causas para instabilidade financeira na teoria ortodoxa}

Na visão convencional de cunho neoclássico, os bancos assumem o papel de meros intermediários financeiros que têm objetivo principal alocar fundos emprestáveis ou oferecer um sistema de gerenciamento de portfólio para os outros agentes econômicos. Nesta visão, a moeda é considerada como neutra, portanto, possuindo essencialmente funções de ser meio de troca e unidade de conta. Criticamente, Papadimitrou e Wray (1999, p. 4), argumentam que essa visão assume uma economia de trocas puras, sendo que o seu modelo é definido "[...] by the design is very "general" - with no money, virtually no institutions [...] no long-lived capital assets and no financial positions".

Com Gurley e Shaw (1955) o setor financeiro passou a ter um papel relevante para a dinâmica do desenvolvimento através das relações e nível das dívidas presentes entres os agentes econômicos. No entanto, a funcionalidade dos bancos no processo de desenvolvimento seria apenas atuar como meros intermediários financeiros. Deste modo, os bancos captam recursos das unidades superavitárias, via

\footnotetext{
${ }^{9}$ Essa questão pode ser bem compreendida nos documentos consultivos do Acordo de Basileia III (BCBS, 2010). Uma afirmação clara neste sentido pode ser encontrada em FMI et al. (2011, p. 8): "[...] in November, the G20 endorsed the FSB's policy framework to address the moral hazards risks and externalities posed by Systemically Important Financial Institutions (SIFIs)".

10 Blanchard e Summers (2017) ressaltam que não existe ainda um modelo teórico único na literatura que compreenda todos os aspectos das crises financeiras.
} 
emissão de títulos e depósitos, emprestando seus fundos para as unidades deficitárias. Em especial, seu papel cresce quando o financiamento do investimento é realizado da forma externa e indireta. Portanto, o papel do sistema bancário seria alocar recursos de maneira eficiente entre os diversos agentes econômicos. Em realidade, o volume de poupança é determinado pela alocação intertemporal do consumo das unidades superavitárias.

Fama (1980) avança no entendimento sobre o papel dos bancos em uma economia de mercado, atribuindo-os uma atuação passiva na economia. O objetivo principal destes seria alocar as riquezas individuais via modificações nos seus balanços patrimoniais, isto é, ofertar um sistema contábil de transferências monetárias via relações de crédito e débito. Ainda, os bancos teriam outra funcionalidade: a de propiciar um sistema de gerenciamento competitivo de portfólio para os seus depositantes, no qual, suas decisões financeiras estão de acordo com o teorema de Modigliani-Miller (1958). Esse teorema implica que os bancos por serem apenas meros intermediários financeiros não teriam nenhuma capacidade de influenciar o resultado de equilíbrio geral da economia (Fama, 1980) ${ }^{11}$.

Para o mesmo autor, a regulação bancária não possuiria o efeito de estabilizar indiretamente a atividade econômica. Isso acontece porque o sistema bancário não exerce influência no sistema de preços, mas aparece no processo de mercado apenas porque a moeda serve como unidade de conta - no qual todos os bem são transacionados - e que, portanto, o sistema bancário ofereceria apenas um serviço de intermediação entre agentes econômicos para contabilizar as diversas transações na economia. Entretanto, o autor reconhece que, na realidade, o sistema bancário é regulado por um Banco Central através do uso de requerimento de reservas compulsórias ou por meio de restrições sobre as remunerações de depósitos. A imposição de se manter reservas compulsórias, por exemplo, criaram apenas um custo adicional (uma espécie de imposto) sobre a remuneração dos depósitos bancários, ou seja, mesmo assim, a essência da competitividade permaneceria inalterada. Neste caso, a oferta de moeda poderia ser controlada pelo banco central via reservas compulsórias.

Ademais, Levine (1997), ao analisar a importância do sistema financeiro para o crescimento econômico, evidencia que os bancos possuiriam o papel de diminuir os custos de informação e transação entre poupadores e clientes, facilitando a troca de bens e serviços na economia. Logo, seu objetivo seria alocar de maneira eficiente

11 Outro resultado teórico relevante deste teorema determina que em uma economia com competição perfeita e mercados completos, a forma de estruturação financeira do balanço patrimonial não é relevante para o resultado de equilíbrio geral. 
a poupança disponível, mitigando os riscos envolvidos nas diversas operações de mercado. De qualquer modo, concluiu-se que nesta literatura, seu papel continua como passivo.

\subsection{As causas para instabilidade financeira na visão convencional}

Apesar da visão convencional adotar como pressuposto que os bancos assumem um papel passivo na economia, esta teoria admite duas fontes principais para a ocorrência de eventuais crises sistêmicas: (i) impactos de choques exógenos que amplificam a exposição de risco sistêmico comum entre as instituições financeiras ou que provoque uma crise de liquidez pela presença do chamado efeito manada; e (ii) a presença de falhas de mercado, seleção adversa e risco moral, que criam um ambiente decisório dos bancos em direcionar para percepções equivocadas ou ineficientes, gerando um maior nível de risco sistêmico.

Em relação ao primeiro ponto, Diamond e Dybvig (1983) apresentam um modelo teórico de corrida bancária, onde uma crise de liquidez seria iniciada pelo impacto de um choque exógeno. Os autores partem do pressuposto de que a funcionalidade do sistema bancário seria oferecer liquidez para os agentes econômicos através da oferta de depósitos que sejam mais líquidos que seus os ativos. A corrida bancária se inicia quando existe uma probabilidade significativa da maioria dos depositantes retiraram seus recursos em um curto período, então, o resultado alcançado provavelmente será um equilíbrio de mercado ineficiente. A crise deriva de uma decisão tomada pelos próprios depositantes, mas alheio ao comportamento do próprio sistema, provocando um movimento do tipo manada. Como consequência, tem-se o início de uma crise de liquidez, que posteriormente, gera efeitos negativos para o restante da economia.

No segundo caso, a teoria das falhas de mercado, partindo do modelo agenteprincipal, aponta que uma das causas para a ocorrência de crises seria a presença de informações assimétricas no sistema financeiro. Essa situação geraria como resultado distorções alocativas na relação entre tomadores e emprestadores através de percepções equivocadas que incentivam os bancos a adotarem decisões mais arriscadas em determinados momentos do tempo. Segundo o Banco da Inglaterra (2009, p. 12), a existência de falhas de mercado cria quatro tipos de resultados para o sistema financeiro: (a) problemas de incentivos que geram consequências inesperadas para a política pública; (b) fricções informacionais que causam os compradores a duvidarem da qualidade dos ativos (seleção adversa) ou quando o agente não consegue observar a atuação do principal (risco moral); (c) a existência de um cenário de decisão com racionalidade limitada; e (d) problemas de coordenação, tal como a presença de caronas (free-riders), portanto, não se podendo atingir uma 
situação estável de equilíbrio.

Com relação aos problemas provocados pela presença de assimetria informacionais, no caso da seleção adversa, Stiglitz e Weiss (1981) demonstraram que seria possível o mercado de crédito apresentar um equilíbrio estrutural com excesso de demanda por fundos. Isso acontece porque os bancos não conseguem determinar, a priori, o retorno futuro dos seus empréstimos, dado que essa informação não lhe está disponível. Portanto, a taxa de juros é utilizada como um mecanismo para revelar a probabilidade de inadimplência dos seus clientes, a fim de selecioná-los.

Borio et al. (2001, p. 1) apresentam um fenômeno denominado de acelerador financeiro. ${ }^{12}$ Inicialmente, o modelo toma como ponto de partida um cenário que apresenta um baixo valor para negociação de colaterais bancários no qual coexiste com um baixo dinamismo econômico. A partir de tal situação, cria-se um baixo incentivo para os bancos concederem empréstimos e financiamentos, devido ao baixo valor e disponibilidade de garantias a serem oferecidas. Quando acontece uma inversão deste cenário, por causa do crescimento da renda, o nível de financiamento externo passará a aumentar de forma bastante acelerada, reforçando posteriormente essa tendência esperada para o ciclo econômico. $O$ resultado seria que o sistema financeiro fica mais compelido em expandir suas atividades apenas em momentos de boom, dado por uma perspectiva que os tomadores teriam uma maior probabilidade de quitarem suas dívidas e oferecerem colaterais de valor mais elevados com uma maior expectativa de ampliação da sua renda futura.

Por fim, a questão do risco moral, em especial, o too big too fail, se torna um problema permanente para os reguladores, na medida em que, a função dos bancos centrais em atuarem como emprestadores de última instância, criam um incentivo para os bancos assumirem riscos crescentes. Isso acontece porque as instituições financeiras partem do princípio de que suas solvências deverão ser garantidas em algum momento no futuro, caso o governo pretenda evitar uma suposta crise de insolvência generalizada que possa resultar em efeitos negativos para economia real. Neste caso, pode-se dizer que a falha de mercado é gerada pela própria atuação governamental.

Desta maneira, conclui-se que para visão ortodoxa do funcionamento do sistema financeiro, qualquer regulação, se necessária, deve ser estabelecida para corrigir as falhas de mercado ou proteger depositantes de uma corrida bancária provocado por um choque exógeno que impactam na sua liquidez. Isso significa que

\footnotetext{
${ }^{12}$ Esse conceito foi anteriormente desenvolvido em um modelo teórico por Bernanke et al. (1999).
} 
teorias econômicas que apontam causas diferentes para crises financeiras como a perspectiva pós-Keynesiana, em particular, as contribuições teóricas dada por Minsky (1982, 1986 [2008], 1992) podem contribuir de maneira significativa em relação ao debate sobre a estabilidade financeira e alternativas para serem conduzidas pelos formuladores de política econômica.

\section{A perspectiva pós-Keynesiana: o papel ativo dos bancos no ciclo econômico}

Por outro lado, a teoria pós-Keynesiana parte do princípio de que o sistema bancário possui um papel ativo na dinâmica econômica, ou seja, consegue influenciar na flutuação das variáveis reais como renda e emprego (Paula, 2014). Esta perspectiva, toma como ponto de partida o conceito de economia monetária de produção para discussão acerca do funcionamento do sistema financeiro. Neste sentido, Paula (2014) aponta que ao considerar um ambiente de incerteza fundamental (KnightKeynes), a moeda seria demandada pela sua capacidade de reduzir o nível de incerteza no processo produtivo, constituindo no ativo líquido por excelência, ou seja, possuindo um baixo custo de transação, caso seja necessário liquidar obrigações financeiras no curto prazo. Ainda, Keynes (1936 [1983]) demonstra que o entesouramento de moeda pelos agentes econômicos não constitui em uma decisão irracional. Em certas situações, a moeda poderia ser mais desejada, mesmo em relação aos outros ativos que oferecessem maiores taxas de retorno. Uma vez que ocorra uma retenção de moeda, dado a hipótese de ampliação da incerteza, haverá um descasamento entre investimento corrente e o investimento desejado, de forma que o resultado será um nível de insuficiência de demanda efetiva. Outro ponto relevante para esse referencial teórico seria que a maior parte das transações econômicas encontrada em uma economia monetária são realizadas em mercados futuros, no qual a renda esperada só pode ser obtida em uma etapa posterior (Paula, 2014). Por consequência, é necessário a existência de uma rede de contratualização, principalmente, quando os empresários precisam adotar posições mais líquidas antes de iniciar o processo produtivo (Keynes, 1937a, 1937b).

$\mathrm{Na}$ prática, em muitos casos, essa disponibilidade de fundos é realizada em uma etapa inicial, por meio de um contrato de crédito pelo sistema bancário. Desse modo, os capitalistas não necessitam dispor de seus próprios fundos, deixando esses recursos para aumentos de capital no futuro ou para pagamentos por eventos inesperados. Por este motivo, para teoria pós-Keynesiana, o sistema bancário é a principal fonte capaz de oferecer o volume necessário de financiamento para as 
decisões empresariais em uma economia monetária de produção. ${ }^{13}$ Neste cenário, bancos passam a ter decisões e motivações próprias, sendo capazes de influenciar a demanda por depósitos (Paula, 2014). Assim, buscam gerir de forma dinâmica seu balanço patrimonial, seguindo um trade off entre liquidez e rentabilidade (Paula, 2014). Portanto, esse fato implica que o sistema bancário possui um papel central e ativo a desempenhar na dinâmica econômica.

Neste sentido, Keynes (1937a, 1937b) evidencia que o crédito bancário permite romper a causalidade preconizada pela economia clássica entre a disponibilidade de poupança prévia e a realização do investimento. Ele explica que existiria uma fonte adicional para demanda por moeda. Uma situação que estaria relacionada ao fato de que durante certa parte do período do investimento, as empresas necessitam manter posições financeiras mais líquidas nos seus balanços, antes de qualquer receita se realize no tempo. Essa demanda por liquidez maior é necessária porque os empresários precisam, por exemplo, adiantar o pagamento dos seus custos de produção. Assim, essa primeira etapa constitui somente em uma gestão contábil de sua operação. Quando o fluxo de caixa gerado pelo investimento é realmente estabelecido, essa demanda maior por liquidez diminui pari passu com o aumento da renda gerada por este investimento planejado.

Em uma etapa posterior, o funding representa como a empresa consegue gerenciar seu fluxo de caixa no tempo, isto é, em que modo é estruturado o prazo de maturidade e a composição de sua dívida no longo prazo. Isso acontece da seguinte maneira: à medida que a renda é auferida, a firma passa a reduzir seus empréstimos de curto prazo (em geral, correspondente ao crédito bancário), modificando para uma estrutura passiva com maiores prazos de vencimento, podendo, por exemplo, ser por meio de emissões de debêntures ou de ações primárias no mercado futuro. Em verdade, o funding corresponde na gestão da poupança que foi gerada de forma expost. $\bigcirc$ lucro realizado valida o investimento produtivo, garantido que as empresas obtenham estruturas financeiras mais robustas no longo prazo (Carvalho, 2016).

Por isso, Keynes explica que o financiamento desejado pelas firmas pode ser ofertado, inicialmente, pelo ajuste nos balanços patrimoniais dos bancos. Depois, este é criado na forma de crédito através de um mecanismo chamado de revolving

\footnotetext{
${ }^{13} \mathrm{Na}$ realidade, as empresas também podem se financiar via lucros retidos, emissão de debêntures e ações primárias ou venda de ativos. De todo modo, como aponta Carvalho (2016, p. 293): "[...] borrowing from banks is, of course, one possible source, but it is not credit provision per se that make it possible to satisfy that demand. Rather, what is needed is to make deposits available to entrepreneurs to accommodate their needs for liquidity. Keynes stressed that is money that matters, not savings".
} 
fund $^{14}$. Logo, existe uma centralidade do sistema bancário em determinar a dinâmica do nivel de investimento, ou seja, "[t]his means that, in general, the banks hold the key position in the transition from a lower to a higher scale of activity" (Keynes, 1937b, p. 668). As condições de financiamento da economia dependem diretamente da relação entre o estado da preferência pela liquidez e pela expectativa de lucratividade futura dos bancos, ou seja, não necessariamente pelo nível da oferta de poupança disponível (Carvalho, 2016; Paula, 2014). Para que o investimento se realize no tempo, portanto, é necessário que os bancos transferiram recursos monetários para as outras firmas via diminuição de sua preferência pela liquidez (Carvalho, 2016). Assim, a criação de moeda pode ser considerada endógena ao sistema: ela é gerada como uma resposta às condições de demanda (investimento e consumo) da economia.

Outro fator importante para decisão de oferta de crédito pelos bancos é o denominado estado de expectativas de longo prazo. Segundo Keynes (1936 [1983], p. 161-162), as firmas tomam suas decisões de investimento se baseando na realização de um prognóstico e no grau de confiança atribuído a ele. Entretanto, esta avaliação, muitas vezes, é feita por meio de estimativas meramente psicológicas. Essas convenções podem ser definidas como prognósticos acerca das tendências econômicas de interesse em que os empresários acreditam que vão se manter durante um certo tempo ou que podem simplesmente tomar como dado uma certa percepção média de mercado, desde que a julguem correta ${ }^{15}$. De todo modo, por estar sempre sujeitos a erros em um ambiente de incerteza fundamental, isso significa na impossibilidade de construir uma distribuição de probabilidade exata de um determinado evento (Davidson, 1982). Portanto, o sistema bancário não irá ofertar crédito, sem que haja uma perspectiva clara que seus ativos terão retorno no futuro, ainda que o cenário corrente possa demonstrar o contrário, ou seja, dependeria também de uma sensação de ânimo e certeza em relação ao resultado futuro do prognóstico que foi realizado: o famoso animal spirits (Keynes, 1936 [1983]).

Vale salientar que bancos, como qualquer agente econômico, também estão sujeitos ao ambiente de incerteza não-probabilística. Em momentos de maior incerteza, bancos irão elevar sua preferência pela liquidez por meio do aumento de suas posições em ativos de curto prazo, ou na ampliação das suas disponibilidades

\footnotetext{
${ }_{14}$ Para maiores explicações do funcionamento desse mecanismo, ver Keynes (1937a, 1937b) e Carvalho (2016).

${ }^{15}$ As firmas também podem adotar a percepção geral do mercado ainda que não a julguem correta. Neste caso, porque acreditam que mesmo que haja um erro no prognóstico, o prejuízo será compartilhado por todos os participantes que o adotaram no mercado. Ver capítulo 15 de Keynes (1936 [1983]).
} 
de caixa e na aquisição de títulos públicos e de renda fixa, ao mesmo tempo, que no lado do passivo, buscam captar uma maior quantidade de depósitos bancários (Paula, 2014). Por outro lado, bancos prefeririam ampliar a sua oferta de crédito, em momentos de boom econômico, passando a ofertar uma maior gama de ativos e de serviços financeiros, transformando seus ativos em prazos de maturidade mais longos, em face da esperança de aumentar sua lucratividade em relação à suas obrigações financeiras neste período ${ }^{16}$. Em outras palavras, o comportamento do sistema bancário estaria relacionado ao seu cenário de lucratividade futuro que, consequentemente, definirá o nível da acumulação de ativos que serão necessários para a validação de sua estrutura passiva.

Posteriormente, a validação inicial desta estrutura de dívida cria um estado de confiança otimista no sistema bancário que faz com que aconteça uma nova rodada de ampliação de crédito. Desta forma:

Do ponto de vista do portfólio de aplicações dos bancos (ativo), como suas expectativas tornam-se mais otimistas na fase ascendente do ciclo, eles passam a privilegiar rentabilidade à liquidez, procurando elevar os prazos e adquirir ativos que embutem maiores riscos, diminuindo a relação entre ativos líquidos/ativos ilíquidos nas suas operações, o que resulta, por exemplo, no crescimento da participação dos adiantamentos e dos empréstimos de mais longo termo em seus portfólios (Paula, 2014, p. 58).

O resultado, entretanto, é uma diminuição sucessiva nas suas margens financeiras, mas que não é percebido ainda como um comportamento arriscado, haja visto que o cenário prospectivo demonstraria ainda que os retornos esperados dos ativos de investimentos na economia continuariam elevados (Minsky, 1985).

Evidentemente, esse estado de confiança poderá ser tornar cada vez mais pessimista, dependendo se as expectativas de longo prazo se tornarem efetivamente frustradas. Caso a rentabilidade do sistema caia em um ritmo significativo, os bancos terão que aumentar seu nível de liquidez. Por consequência, diminuindo sua oferta de crédito com uma elevação da taxa de juros cobrada sobre seus empréstimos, ou seja, provocando uma mudança nas condições de financiamento da economia. Porém, neste novo momento, o sistema bancário se encontrará em uma estrutura financeira mais fragilizada que no período inicial do ciclo econômico. A partir dessa situação, Minsky (1992) demonstra que a fragilidade financeira é construída com base na relação dada entre o ritmo obtido do fluxo e o estoque de renda passada dos agentes econômicos e as suas obrigações e compromissos financeiros dado pela relação entre estoque de dívida e taxas de juros acordadas no tempo. Neste sentido,

${ }_{16}$ Outro fator é que neste período também seria mais fácil dar colaterais com valores mais elevados que podem ser dados em garantia em empréstimos, portanto, influindo do ponto de vista do sistema bancário para a diminuição da sua percepção de risco. 
ele classifica essa relação entre três tipos de posturas financeiras alternantes ao longo do ciclo: hedge, especulativo e Ponzi ${ }^{17}$.

Unidades do tipo hedge são caracterizadas por ter um fluxo de caixa esperado com uma certa margem acima das suas obrigações financeiras em qualquer ponto relevante do tempo. Desta forma, uma unidade hedge não é afetada diretamente de forma adversa por mudanças nas condições de financiamento nos mercados financeiros (Minsky, 1982, p. 39). Porém, essa unidade pode ir para uma posição mais fragilizada, caso o seu fluxo de caixa ou valor dos seus ativos caiam de forma permanente em um dado momento, piorando a sua capacidade de honrar suas obrigações financeiras de forma significativa. Em seguida, unidades especulativas conseguem apenas pagar os juros sobre suas dívidas, entretanto, sem modificar o tamanho do seu principal, mas sendo que em certos momentos, as obrigações financeiras podem exceder seu fluxo de caixa esperado. Em caso de dificuldades, esse tipo de unidade pode incorrer em uma ampliação do seu financiamento externo. Evidentemente, esse tipo de estrutura de dívida poderá estar mais sujeito às flutuações nas condições de financiamento como no aumento do nível da taxa juros de mercado. Por último, uma estrutura financeira do tipo Ponzi não conseguiria pagar, na maioria das vezes, sequer os juros da dívida ou amortizar seu principal, pelo menos com seu fluxo de caixa presente. Por este motivo, para continuar suas operações, a firma precisa liquidar parte dos seus ativos ou ampliar ainda mais seu nível de financiamento externo. Em geral, essa unidade é caracterizada por possuir um alto nível de alavancagem financeira.

De todo modo, segundo Minsky (1982, p. 41), a estabilidade do sistema econômico pode ser representada pela agregação dessas diferentes posturas financeiras das unidades econômicas ao longo do tempo. Neste sentido, uma economia mais robusta no longo prazo possuiria uma maior quantidade de unidades do tipo hedge em comparação com as do tipo especulativo e Ponzi. Por outro lado, uma economia com mais unidades Ponzi estará muito provavelmente sujeita a uma crise financeira, dado que as estruturas deste tipo, acabam-se demonstrando insustentáveis no longo prazo.

Kregel (1997) afirma que a evolução da fragilidade no sistema financeiro depende da chamada margem de segurança. A evolução para um sistema mais fragilizado (do tipo Ponzi), deve-se ao fato de que o sistema não conseguiria avaliar

\footnotetext{
17 Segundo Minsky (1982), qualquer unidade econômica sejam estas firmas não-financeiras, bancos, governos ou famílias, podem ser representadas como uma estruturação de dívida de um balanço patrimonial, portanto, sujeitas a sua hipótese de fragilidade financeira.
} 
precisamente o risco do devedor no decurso do tempo, diante de ambiente decisório sempre incerto, no qual a avaliação das operações depende do estado de expectativas futuras da economia. Desta forma, um das formas utilizadas pelos bancos para construir a avaliação da oferta de crédito se torna por meio de uma estabelecimento de uma convenção coletiva baseado nas informações passadas de disponibilidade de pagamentos dos seus clientes, ou seja, com base no seu passado de crédito, acreditando que as condições de retornos passados poderão ser repetidos no presente (Kregel, 1997, p. 544). Em outros palavras, dado a incapacidade de construir uma distribuição exata dos eventos, o passado pode acabar se tornando o melhor guia para as expectativas futuras, pelo menos, quando as condições econômicas não são modificadas de forma significativa. Assim, em momentos de maior euforia, o sistema econômico começa a se direcionar paulatinamente de uma posição do tipo hedge para especulativa, no sentido de que os bancos passam a atuar em projetos de investimento considerados cada vez mais arriscados em busca de uma maior rentabilidade, dado por uma percepção prevalecente de que existiria uma baixa probabilidade dos seus devedores em não honrarem seus compromissos em um futuro próximo. Entretanto, essa avaliação é geralmente realizada sob as convenções psicológicas dentro do estado de expectativas de longo prazo, sendo puramente precárias e voláteis, visto que o retorno futuro de um determinado ativo no qual se depende esta mesma margem de segurança é sempre incerto. Consequentemente, acontece um aumento constante do endividamento do sistema por meio do alongamento dos prazos dos seus ativos e do aumento do seu passivo no curto prazo, ou seja, causando um descasamento contínuo entre esses prazos de maturidades encontrados no seu balanço patrimonial (Paula, 2014).

Segundo Kregel (1997), a construção da fragilidade financeira por meio da diminuição imperceptível das margens de segurança e é um resultado natural da busca por uma maior rentabilidade tanto por parte dos bancos como de seus clientes, ou seja, representa a própria dinâmica do investimento de uma economia capitalista que depende do sistema bancário para criar adiantamento de liquidez (Paula, 2014.) Tendo isso em vista, esse comportamento não pode ser considerado fraudulento ou irracional, mas porque os bancos não conseguem reconhecer que suas margens de segurança estão realmente sendo erodidas, dado que a euforia do boom econômico reforça uma convenção que essa tendência de alta lucratividade irá se manter no tempo. Portanto, pode-se concluir que a teoria da fragilidade financeira possui uma visão que a instabilidade financeira não é gerada por fatores exógenos como movimentos irracionais dos agentes econômicos ou por falhas de mercado, no qual a instabilidade poderia ser garantida por meio de regulação bancárias, mas representam a essência natural de como funciona o sistema capitalismo moderno 
(Kregel, 1997). O resultado teórico que se depreende seria que o funcionamento do sistema financeiro é inerente instável, sendo que a fragilidade financeira é construída exatamente nos momentos de expectativas mais otimistas, isto é, no qual aparentemente os balanços das firmas demonstram estar mais sólidos (Minsky, 1992).

O sistema bancário pode ser direcionado de forma não-intencional para uma estrutura do tipo Ponzi, principalmente, por esta erosão constante de suas margens de segurança. Caso essas margens já sejam mínimas, um choque adverso que implique em uma redução do fluxo de caixa esperado do sistema, tal que seu fluxo de caixa não se realize no curto prazo, promoveria uma modificação inesperada nas suas decisões de portfólio. Desta forma, as condições de liquidez se restringem, ou seja, rompendo com a validação inicial da expansão do investimento e do preço dos ativos, impondo que o sistema financeiro passe a vender de maneira crescente esses mesmos ativos em busca de um maior nível de liquidez. Entretanto, segue-se como resultado uma queda nos preços de todos os ativos da economia. No final, "[t]he result is a Fisherian debt-deflation process, which produces falling prices, rising real debt burdens, and the reversal of the normal laws of supply and demand. Lower prices increase supply and reduce demand" (Kregel, 1997, p. 543).

$\mathrm{Na}$ realidade, uma crise financeira acaba se tornado uma crise keynesiana clássica de insuficiência de demanda efetiva, isto é, porque ao ocorrer uma frustração significativa das expectativas de lucratividade da suas operações ativas (alta inadimplência) dos bancos, no qual leva para restrição da oferta de crédito, este fato consequentemente, afeta o fluxo de investimento e, por fim, toda a economia real. Todavia, por causa das estruturas de dívidas mais arriscadas que foram construídas no período de tranquilidade econômica, foi criado as bases para sua própria destruição. Percebe-se também que essa instabilidade não aconteceu apenas porque o sistema foi impactado por um choque adverso exógeno como um aumento da taxa de juros, mas porque o sistema já se encontrava no limite de sua fragilidade financeira, um cenário construído em um momento anterior a este fato. Por este motivo, aparentemente, qualquer movimento como uma simples ventania, acaba-se por se assemelhar a um verdadeiro furacão na economia.

Esse resultado define que um aumento da fragilidade financeira sempre precede a própria instabilidade econômica. Em geral, uma crise financeira é um resultado de um crescente desequilíbrio estrutural de dívidas dos agentes econômicos conjugado com uma mudança nas condições financeiras, sendo representado por uma restrição abrupta da disponibilidade de liquidez. Nas palavras de Kregel (1997, p. 543): "Minsky's main contribution to description of these events 
was to point out that they were inevitable. He formulated them as an endogenous process in which sustained economy stability produced financial fragility". De fato, como será exposto a seguir, essa construção da fragilidade no tempo possui uma fonte adicional importante para sua expansão durante o ciclo econômico, no qual a regulação bancária como a política macroprudencial encontra um limite evidente para sua eficácia: a introdução de inovações financeiras.

\subsection{O limite da regulação bancária: a "destruição criativa" das inovações financeiras}

Minsky (1988) discute, com base na teoria da destruição criativa de Schumpeter, que as inovações introduzidas pelo sistema financeiro podem ter um papel desestabilizador na dinâmica econômica. Isso acontece porque o sistema capitalista é sustentado pela acumulação privada de ativos de capital no qual o sistema financeiro tem a capacidade de prover o seu financiamento. Na visão schumpeteriana, "[m]oney is never neutral and the credit mechanism as administered by banks and financiers is necessary for development" (Minsky, 1988, p. 9). A interação entre o setor real e financeiro permite que se obtenha novos produtos e serviços financeiros que são criados a fim de satisfazer uma demanda crescente por financiamento da economia ${ }^{18}$. Nas suas palavras:

New combinations, which result from the outcomes of negotiations among entrepreneurial businessmen and financiers, lead to process and product innovations as well as new financial relations and financial institutions. Those who finance a Schumpeterian innovator always have a novel problem in structuring the financing. Two sets of new combinations, in production and finance, drive the evolution of the economy (Minsky, 1988, p.3).

Essas inovações financeiras, em geral, surgem com objetivo de serem substitutos imperfeitos em relação à moeda fiduciária, ou seja, podendo ser consideradas como quase-moedas. Assim, expande-se as fontes possíveis de liquidez na economia, como uma espécie de multiplicador, proporcionando novas oportunidades de lucros para o sistema financeiro. Inovações são criadas pelo sistema bancário, principalmente, após a introdução de regulações financeiras. Isso acontece porque este fato representa uma ameaça crível para a expansão do seu nível de atividade e lucratividade. Ainda, inovações financeiras são utilizadas para criar novas formas de composição e gerenciamento do balanço patrimonial, ou seja, criando

\footnotetext{
18 Segundo Minsky (1988), o sistema capitalista pode ser caracterizado por diferentes "fases" evolutivas de acordo com a influência das finanças sobre a dinâmica econômica que buscam novas oportunidades de lucro. Ele cita ao menos quatro fases: o Capitalismo Comercial ("Commercial Capitalism"), Capitalismo Financeiro ("Finance Capitalism"), Capitalismo Gerencial ("Managerial Capitalism") e o Capitalismo Gerenciador de Dinheiro ("Money Manager Capitalism"), este último correspondendo a fase que a economia mundial vem vivenciando nas últimas décadas.
} 
espaços para o aumento da alavancagem financeira.

Desta forma, as inovações são geradas de forma endógena, isto é, funcionam como mecanismo para criar oportunidades para burlar as regulações que foram estabelecidas como uma tentativa de retomar sua obtenção de lucro no período anterior ${ }^{19}$. Neste sentido, as regulações financeiras poderiam ter um efeito limitado no decurso do tempo, haja vista que esse comportamento do sistema bancário poderia modificar as condições de financiamento da economia. Desta maneira, as intervenções governamentais poderiam passar apenas uma sensação temporária de tranquilidade no sistema econômico. Enquanto, na realidade, os bancos aumentam novamente sua fragilidade financeira através desses novos serviços financeiros que ainda não foram compreendidos (e regulados) pelos supervisores bancários. Em um outro ponto de vista, os bancos poderiam ser compelidos a atuarem em projetos cada vez mais arriscados por uma falsa percepção que esses serviços poderiam prover uma melhora na sua rentabilidade futura ou na diminuição do seu risco de crédito, mas que em realidade, tem como resultado uma probabilidade maior de diminuição nas suas margens de segurança. Isso significa que a obtenção da estabilidade financeira não pode ser definida sob um referencial estático ou onde a atuação dos bancos é sempre passiva, isto é, possuindo um papel de serem meros intermediários financeiros. Dentro desta perspectiva, pode-se concluir que não existe razão teórica para compreender que a concepção da política macroprudencial, com base na sua formulação dentro da visão convencional do papel do sistema bancário possam atingir o seu objetivo pretendido, especialmente, porque não atuam para conter os efeitos potenciais de possíveis novas inovações financeiras sobre a dinâmica de financiamento das economias capitalistas modernas, assim, que tornam essas práticas regulatórias inválidas no decurso do tempo.

Ademais, mesmo que teoria macroeconômica convencional, que dá suporte teórico a política macroprudencial, tenha avançado sobre certos aspectos dentro do debate da estabilidade financeira pós crise de 2008, tal como: 1) reconhecer o comportamento pró-cíclico do sistema bancário (Borio et al., 2001; Borio, 2003, Bernanke et al., 1999; Shin, 2013); 2) que parte da formação de risco sistêmico possa ter um caráter endógeno na decisão de portfólio (Borio, 2003; Borio, 2016; Lowe, 2002); 3) que a política monetária possa ter resultados não neutros no longo prazo (Borio, 2016; Jordà et al., 2020); e 4) incluí um sistema financeiro e fricções (rigidez) financeiras nos modelos de equilíbrio geral (Carvalho e Castro, 2016; Quint e

19 Nas palavras de Guttmann (2008, p. 19): "Os bancos usam a inovação para debilitar as regulamentações existentes, com vistas apenas a ampliar em demasia a sua liberdade recémdescoberta, criar condições de crise e assim invocar uma nova regulamentação como resposta" 
Rabanal, 2013), porém, esses avanços não corresponderiam exatamente a essência do problema encontrado por Minsky (1986 [2008]).

De fato, para Minsky (1992) a fragilidade financeira é um resultado normal e funcional do capitalismo moderno, dado que a sua lógica é ser um sistema de produção organizado em tornos das finanças, no qual a decisão de investimento das firmas é altamente especulativa e depende crucialmente do papel ativo do sistema financeiro em sancionar adiamentos de liquidez, porém, com ambos estando sujeito em um cenário de incerteza não-probabilística. De acordo com Minsky (1992, p. 6) "[i]nvestment take place now because businessmen and their bankers expect to investment to take place in the future". Uma crise inesperada representa um rompimento desta relação financeira, tornando-se inevitável diante das falhas de realização dessas expectativas otimistas. Logo, não é possível compreender o fenômeno da instabilidade financeira como sendo apenas o resultado de uma causa de falha de mercado ou de choques exógenos, discutidos por meio de modelos de equilíbrio geral, assim, para que solução em relação estabilidade financeira estaria plenamente garantida através da introdução de políticas macroprudenciais.

Por outro lado, na visão minskyana, o fator que deve ser considerado como necessário para aumentar a estabilidade do sistema financeiro estaria, na realidade, na estabilização das suas próprias fontes de lucratividade futura, ou seja, em como garantir a capacidade de retorno esperado das suas operações ativas. Pode-se afirmar neste sentido, porque segundo os pressupostos da hipótese da fragilidade financeira, a instabilidade depende de como foram estruturadas o nível de fluxo de caixa e preferência pela liquidez dos bancos e a sua relação com posturas de dívidas e estoque de riqueza dos outros agentes econômicos (famílias e firmas não-financeiras) que validam a expansão de crédito durante a fase ascendente do ciclo econômico, mas que por sua vez, estão ligados às condições de financiamento da economia em geral (como a taxa de juros) e da realização das suas expectativas de lucros futuros. Desta maneira, uma solução passaria pela tentativa de estabilização do próprio nível da atividade econômica. Em outras palavras, para estabilizar a oferta de crédito é preciso estabilizar também a demanda por crédito, representado pela taxa de investimento (lucro) das firmas não-financeiras e o consumo das famílias, que por sua vez, depende do nível do déficit do governo e das exportações líquidas (derivado da relação encontrada por Kalecki (1954 [1977])) e, que em última instância, dependerá da proximidade da atividade corrente do nível de pleno emprego, isto é, uma ideia levantada inicialmente por Keynes (1936 [1983]).

Nesta perspectiva, portanto, a busca da estabilidade financeira dependerá mais da adoção de políticas econômicas de alcance do pleno emprego, do que 
necessariamente de restrições impostas por regulações financeiras, em particular, porque os bancos atuariam constantemente para criar inovações que sejam capazes de burlar as regulações estabelecidas em busca de uma maior rentabilidade, ampliando novamente a sua fragilidade financeira. Porém, ressalta-se que não significa que por causa desse motivo, as regulações bancárias não precisam ser necessariamente introduzidas pelos governos ou organismos internacionais ( $\mathrm{e}$ podendo até mesmo serem suprimidas como prefeririam algumas vertentes econômicas mais liberais), mas apenas pretende-se apontar que esse de tipo de política possui certas limitações em relação ao que se pretende atingir no tempo. Deste modo, é preciso encontrar uma política econômica alternativa que pretenda suavizar os efeitos decorrentes de um processo minskyano de fragilidade financeira (Minsky Moment), indo além da abordagem macroprudencial. Portanto, o presente artigo propõe em acordo com a conclusão que instabilidade financeira é de caráter essencialmente endógeno e inevitável no longo prazo, uma proposta seria adotar de maneira conjunta as três políticas econômicas ativas de estabilização sugerida por Minsky (1986 [2008]): Big Bank (Lender of Last Resort), Big Government e Big Employment (Employer of last Resort). Desta forma, o Big Bank atuará para manter a liquidez do sistema financeiro e sustentação dos preços dos ativos. $\bigcirc$ Big Government e Big Employment pretende impedir uma queda acentuada na renda das empresas e famílias. Ambos criam condições para que a demanda por crédito se mantenha e não ocorra um aumento inesperado da inadimplência, provocando um episódio de estresse financeiro.

\section{Uma proposta alternativa pós-Keynesiana para estabilização do sistema financeiro}

Minsky (1986 [2008]), defende que o banco central atue como emprestador de última instância para impedir um processo de deflação de dívida. Seu argumento se deve a constatação sobre a capacidade do banco central em acessar os balanços do sistema bancário, tendo condições suficientes para controlar a expansão de crédito através de uma gestão eficiente dos canais de liquidez. No caso da probabilidade do início de uma grave recessão, o banco central poderia garantir a liquidez do sistema bancário de forma rápida através de uma maior oferta de moeda na economia ${ }^{20}$. $\bigcirc$ objetivo, principalmente, seria atuar como um emprestador de última instância refinanciando as estruturas de portfólios do sistema bancário e

\footnotetext{
${ }^{20}$ De fato, durante a crise de 2008, o governo adotou a política do "Quantitative Easing" consistindo em uma política monetária não convencional (sob uma taxa de juros próximo de zero) de expansão da base monetária e compra de ativos financeiros.
} 
aceitando colaterais das firmas não- financeiras com baixo valor de mercado, caso sejam necessários, impedindo um processo de deflação de dívida que tem por deflagração uma venda de ativos para obtenção de caixa pelos bancos, cujo efeito decorrente afetaria negativamente a economia real. Em outros termos, essa política permite achatar a curva longa da taxa de juros por meio da compra de títulos privados de maior risco, assim, permitindo controlar o comportamento defensivo do sistema financeiro em restringir acesso a liquidez em meio a este cenário de aversão ao risco e expectativas mais pessimistas (Minsky, 1986[2008]) ${ }^{21}$.

Desta maneira, sua proposta seria de um papel ativo desta instituição como um formulador de política econômica que vai muito além do objetivo de controlar a dinâmica inflacionária, como atualmente é defendido pela teoria macroeconômica convencional. Segundo Kregel (2014), sua atuação deveria ser vigilante e ativa em todo tempo para que este esteja sempre preparado em vista de uma crise iminente. Uma política de regulação financeira que fosse estabelecida pelo banco central precisaria ser realizada de maneira dinâmica, ou seja, reconhecendo também os efeitos decorrentes do processo de fragilidade financeira endógena e das constantes inovações que são introduzidas pelo sistema bancário que afetam o ciclo econômico (Kregel, 2014). Porém, Minsky (1986) acredita que o papel de emprestador de última instância e regulador não garante necessariamente a estabilização do sistema financeiro. Na sua visão, é preciso que seja estabilizado a própria fonte de lucratividade do sistema bancário, que em última instância, pode ser representado pelo nível da demanda agregada da economia.

\subsection{A política do "Big Government": a sustentação do gasto autônomo em última instância}

Minsky (1986) aponta que uma participação ativa do governo constitui em uma das principais fontes para manutenção das margens de lucros privados em uma economia capitalista. $\bigcirc$ déficit orçamentário poderia atuar como um instrumento contracíclico, principalmente, em momentos de expectativas mais pessimistas. Seu objetivo seria manter a expectativa de demanda futura dos agentes econômicos e atuando como um complemento para os gastos privados. Na sua visão, o governo deve ser grande o suficiente para que seu déficit mantenha a taxa de investimento e o consumo das famílias, de tal soma que impeça que ocorra um início de uma espiral deflacionária e aumento do desemprego (Vasconcelos, 2014). Nesta perspectiva, o gasto público não gera um crowding-out, como supõe a teoria macroeconômica

\footnotetext{
${ }^{21} \mathrm{Na}$ prática, "[t]his involves operations that replace private liabilities with Federal Reserve liabilities and the absorption of private losses by the Federal Reserve or other agencies" (Minsky, 1986, p. 51).
} 
convencional, mas um crowding-in. Em uma recessão, esse gasto é complementar e não substituto em relação a demanda do setor privado. Ainda, o déficit orçamentário permite que os agentes econômicos concentrem a maior parte dos seus recursos excedentes em títulos do Tesouro (algo que é necessário para financiar essa soma elevada de gastos totais), ou seja, oferecendo um ativo altamente líquido para composição de portfólio que possui um baixo risco de inadimplência.

Para defender esse ponto de vista, Minsky $(1986,1992)$ se utiliza da relação entre os gastos do governo, a taxa de lucro dos capitalistas e o nível de investimento que é deduzido pela equação da determinação de lucros encontrada em Kalecki (1954 $[1977): P=I+(C-W)+(G-T)+(X-M)$. Sendo que $P$ corresponde à parte da renda na forma de lucro dos capitalistas, $C$, o consumo agregado, $I$, o investimento agregado, $W$ a parte da renda que corresponde a massa de salários dos trabalhadores, Go gasto do governo, $\mathrm{T}$, a arrecadação tributária, $X$, o volume de exportações e $M$, de importações. Desta forma, (G-T) corresponde o déficit (superávit) orçamentário do governo e (X-M), o saldo da balança comercial.

Primeiramente, se tomarmos a premissa Kaleckiana que "os trabalhadores gastam o que ganham e os capitalistas ganham o que gastam”, ou seja, todo lucro retido é gasto em investimento e que todo salário é gasto em consumo e, ainda, se supor uma economia fechado e sem governo, então $P=I$ : a taxa de lucro será igual à taxa de investimento no agregado somado ao consumo privado ${ }^{22}$. Se incluirmos novamente, a atuação do governo na equação, isso sinaliza que um déficit orçamentário corresponderá em um aumento da taxa de lucro (investimento) dos capitalistas $^{23}$. Neste sentido, um déficit governamental representaria uma forma de sustentação da taxa de investimento da economia.

Essa atuação do governo permitiria criar um espaço para a estabilização da taxa de lucro do sistema bancário, dado que seu comportamento é correlacionado positivamente com o próprio nível de atividade da economia. Ao manter o nível de demanda agregada por meio da expansão fiscal contracíclica, as firmas nãofinanceiras conseguiram ter a capacidade de aumentar seu investimentos pelo aumento da expectativas de vendas futuras, então, aumentando seu fluxo de caixa, possibilitando retornar seus débitos ao longo do tempo, portanto, mantendo estável a oferta de crédito. Segundo Merhling (1999) "[g]overnment intervention is able to

\footnotetext{
22 Possas (1999) aponta que para o princípio da demanda efetiva, a variável crucial para dinâmica econômica é o nível dos gastos autônomos dos agentes econômicos e que a causalidade teórica encontrada por Kalecki é do nível do investimento para taxa de lucro.

${ }^{23}$ De acordo com as contas nacionais: se $(X-M)=0$, então, o déficit do setor público $(G-T)=$ superávit do setor privado (S-I), onde S é a poupança privada e I e investimento privado.
} 
forestall a crisis because it can relax the survival constraints of the private agents without tightening any survival constraints anywhere else". Consequentemente, esse mecanismo leva para uma estabilização da taxa de lucro do sistema bancário e que garante a consolidação de uma estrutura financeira mais robusta, ou seja, do tipo hedge no longo prazo $^{24}$. Assim, o sistema não poderá estar sujeito a sofrer uma grave crise sistêmica advindo de choque externos como elevação repentina da taxa básica de juros.

Desta forma, segundo Vasconcelos (2014, p. 26), os gastos do governo tem um papel de gerar três efeitos sobre a renda dos agentes econômicos, consistindo em: (a) um efeito renda e emprego, dado que o déficit aumenta a demanda governamental diretamente de mercadorias, serviços e contratação da sua própria força de trabalho (b) o efeito orçamento (positivo ou negativo), dado pelo impacto do gastos no balanço financeiro de diferentes setores da economia por meio de compras governamentais, por exemplo, na contratação de empresas para executar obras, em serviços de infraestrutura; (d) efeito portfólio, no qual a emissão da dívida pública garante o pagamentos de renda em forma de juros para seus detentores, portanto, representando uma fonte de receita menos arriscada em relação aos outros ativos da economia ${ }^{25}$.

Minsky (1986[2008]) toma como um exemplo para este argumento do papel do déficit para estabilidade financeira, a evidência histórica encontrada no período das décadas de 1970-1980, na economia dos Estado Unidos, no qual apesar de todos os sinais para um quadro parecido com a crise de 1929, a crise econômica não aconteceu de fato. Na sua perspectiva, essa contradição pode ser explicada dada por uma proporção maior do gasto do governo em relação ao Produto Interno Bruto (PIB) neste período. Esse gasto era realizado, principalmente, através da oferta de uma ampla rede de proteção social baseada em esquemas de transferência de renda, gastos com educação, oferta de subsídios para empresas, além do crescente volume de recursos que foi despendido com setor militar do país.

Por outro lado, Minsky (1986 [2008]) salienta também que nem todos os gastos efetuados pelo governo teriam sempre os mesmos efeitos sobre a demanda agregada. Sua preocupação era que os gastos com transferências de renda como a

\footnotetext{
${ }^{24}$ Cabe salientar que a taxa de lucro não precisa necessariamente ter um nível elevado, mas apenas como é definido pelo conceito de uma postura financeira do tipo hedge, ou seja, que se tenha como resultado a garantia de uma boa margem de segurança em relação às suas obrigações financeiras para firma em qualquer ponto no tempo.

25 Minsky (1986 [2008], p. 24) esclarece que a macroeconomia convencional aceita apenas os efeitos renda e orçamento do gasto do governo, portanto, negligenciando o papel do efeito portfólio. Isso significa que a política fiscal tem um impacto maior que o usual.
} 
implementação de uma renda básica universal permanente, apesar de serem meritórias para a maioria da sociedade, por outro lado, poderia ainda gerar uma tendência inflacionária. ${ }^{26}$ Seu argumento em relação a esse ponto, seria que este tipo de gasto não é capaz de promover um efeito multiplicador Keynesiano na mesma magnitude do que se poderia ser obtido com a expansão do investimento público na realização de grandes projetos de infraestruturas ou na contratação direta de mão-deobra pelo Estado, principalmente, em momentos de crise ou depressão econômica. Portanto, ele defende que a luta contra a pobreza e a desigualdade de renda que perfaz o sistema capitalista poderia ser mais eficiente se tivesse um comprometimento dos formuladores de política econômica com objetivos de atingir o nível de pleno emprego da economia através do chamado Big Employment ou Employer of Last Resort. Assim, apesar desta política possa ser considerada dentro do Big Government, difere-se por ter um caráter permanente e voltado para um objetivo específico, isto é, da promoção do pleno emprego.

\subsection{A política do "Big Employment": o Estado como empregador de última instância}

Para Minsky (1986 [2008]), diferentemente do gasto com transferência de renda, dar condições de emprego para sociedade seria algo superior, pois, ampliaria a produtividade via treinamento da mão-de-obra e experiência que será adquirida ao longo deste processo, além de oferecer uma capacidade ao trabalhador em não ficar sempre dependente dos benefícios dados pelo Estado.

Na visão de Wray (1998), isso seria possível através da implementação de um programa de emprego universal permanente que contrataria a mão-de-obra não capitalizada pelo setor privado. A solução, portanto, deveria ser implementar uma política permanente de pleno emprego, no qual inclusive este fosse capaz de promover uma estabilidade do nível de preços no longo prazo. Nesta perspectiva, um caso histórico usualmente citado como exemplo para implementação de um programa de emprego universal é o New Deal - a política de recuperação econômica adotada nos Estados Unidos durante o Governo de Franklin D. Roosevelt depois do Crash da Bolsa de 192927. Posteriormente, depois de constatados os efeitos da crise financeira de 2008 sobre a economia dos Estados Unidos, a defesa da implementação

\footnotetext{
${ }^{26}$ Minsky esclarece que esse tipo de gasto é importante para aumentar a demanda agregada no curto prazo, mas não implica necessariamente em capacidade de produção da economia, pois, criaria uma barreira para induzir uma maior participação da mão--de-obra no produto (Vasconcelos, p.29).

${ }^{27}$ Tcherneva (2018, p.55) aponta que "Ii]n many ways, the New Deal invented the model of largescale direct employment programs during the Great Depression. An estimated 13 million workers participated in the Works Progress Administration (WPA)—the largest of the job's programs".
} 
de políticas para o pleno emprego e seus desenhos de configuração foram retomadas na literatura (Tcherneva, 2018; Wray, 1998).

Em geral, o objetivo é criar um programa de emprego universal em vista de garantir um volume de emprego que não pode ser absorvido em um determinado momento pelo setor privado, principalmente, em momentos de crise sistêmica, no qual a taxa de desemprego se acelera. Seu princípio pode ser resumido na seguinte frase:

The job guarantee (JG) is a public option for jobs. It is a permanent, federally funded, and locally administered program that supplies voluntary employment opportunities on demand for all who are ready and willing to work at a living wage" (Tcherneva, 2018, p. 1).

Teoricamente, permite-se gerar uma oferta infinitamente inelástica de mãode-obra, mas estabelecendo um "salário mínimo" socialmente aceitável abaixo da média do mercado privado. Fica claro que a implementação de uma política econômica deste nível de complexidade certamente demandaria um aumento significativo do gasto público no longo prazo ${ }^{28}$. Portanto, a discussão se volta para como criar as condições políticas para seu financiamento.

Primeiramente, pelo ponto de vista da teoria macroeconômica convencional, o gasto do governo poderia gerar efeitos negativos na economia com impactos inflacionários, caso fossem realizados simplesmente pela expansão da moeda fiduciária ( ou seja, sem a sua acomodação com emissão de títulos públicos), ou poderia ter efeitos de substituir investimento privado por investimento público (crowding out), além de que existiria uma possibilidade dos governos em não poderem rolar as suas dívidas no curto prazo, em caso dos investidores não terem confiança na gestão da dívida pública, normalmente confrontado com o aumento de alguns indicadores de risco como a relação de dívida/PIB e risco-país (Wray, 1998). Ainda, os governos também seriam coniventes com uma certa taxa de desemprego involuntário porque acreditam que este seja um mal necessário, dado pela hipótese do tradeoffentre inflação e desemprego elencado pela Curva de Phillips (Tcherneva, 2018, p. 3).

Por outro lado, os defensores de uma política voltada para o pleno emprego utilizam como suporte teórico a chamada Teoria Monetária Moderna (MMT), sendo influenciada por diferentes correntes teóricas heterodoxas como a das finanças funcionais de Abba Lerner (1943), na chamada Teoria Cartalista para origens da

\footnotetext{
${ }^{28}$ Entretanto, Wray (1998) aponta que esse déficit somente deve ser o suficientemente para atingir o nível de pleno emprego da economia. Acima deste ponto, ele concorda com a hipótese de que poderia criar uma inflação de demanda.
} 
moeda, em que alguns dos seus expoentes estão Knapp e Innes, pela influência dos trabalhos de Keynes (1936 [1983]), Minsky (1982, 1986 [2008], 1992), Kalecki (1954 [1977]) e de outros pós-keynesianos ${ }^{29}$. Em contraposição à teoria ortodoxa, esta teoria afirma que déficits orçamentários não constituem empecilhos para atuação do Estado na economia, inclusive podem ser considerados até necessário para que se possa impedir pressões deflacionárias sobre nível de preços e ativos financeiros (Wray, 1998).

Deste modo, esta perspectiva teórica adota como hipótese que um país não pode se tornar insolvente enquanto puder emitir totalmente a sua dívida pública na sua própria moeda, ou seja, é necessário que o país detenha um conceito classificado de soberania financeira ${ }^{30}$. Nesta situação, o Tesouro sempre poderá a honrar sua emissão de dívida, dado a taxa de juros vigentes ${ }^{31}$. Ademais, o gasto do Estado não é limitado pelo seu orçamento, pois, ainda o gasto precede a arrecadação, mas pela capacidade que este mesmo de despender a moeda fiduciária em compra dos bens e serviços que são disponibilizados pela sociedade ${ }^{32}$. Então, no caso de uma economia com alta capacidade ociosa e expectativas mais pessimistas, existe uma possibilidade de mobilizar recursos sem diretamente afetar o nível de preços. Consequentemente, um aumento do déficit público em favor de políticas para atingir o pleno emprego e que consiga contratar por um valor mínimo por todos aqueles trabalhadores que estão dispostos a trabalhar, por exemplo, poderia ser realizado simplesmente através da emissão monetária ou aumento de dívida pública de âmbito interno. Isso significa que as restrições impostas pelo mercado como a implementação de regras fiscais rígidas são, na realidade, auto impostas pelos próprios governos, pois, tem-se a percepção que deveriam cumprir esses certos preceitos orçamentários em vista de conseguir rolar as suas dívidas no curto prazo junto aos investidores internacionais.

\footnotetext{
${ }^{29}$ A visão Cartalista aponta a origem da moeda como uma imposição tributária do Estado contra seus residentes. Neste sentido, os impostos são utilizados para retirar moeda em circulação e manter a sua demanda estável no tempo.

${ }^{30}$ Outro pressuposto importante seria que o regime cambial deva ser do tipo flutuante, ou seja, de forma que o Banco Central não se comprometa em manter uma paridade com uma moeda estrangeira. Porém, pode-se argumentar em relação com base na teoria das hierarquias de moedas, esse espaço de expansão fiscal pode ser ameaçado, caso a sua moeda não seja plenamente conversível no sistema de pagamento internacionais, garantindo um alto nível de liquidez nas suas transações cotidianas. Neste caso, é possível que ocorra uma fuga de capital com uma desvalorização abrupta da taxa de câmbio, dependendo da preferência da liquidez dos agentes internacionais. Para uma discussão crítica deste conceito, ver Vergnhanini e Conti (2017).

31 No limite, o governo pode fazer uma emissão monetária via Banco Central e pagar os juros sobre os títulos de dívida. Ver Lerner (1943).

32 Para uma discussão sobre a hipótese de precedência do gasto e arrecadação e suas restrições institucionais, ver Cesaratto (2016).
} 
Entretanto, assim como o gasto governamental com relação à política fiscal, um programa de emprego universal deve ter como característica um papel contracíclico, pois, na medida em que a economia cresce pela maior expectativa de demanda, o setor privado passa a aumentar pari passu o seu nível de contratação. Deste modo, este programa deveria atuar como uma espécie de um estabilizador automático (buffer): aumentando sua dimensão em momentos de recessões e diminuindo, em momentos de expectativas mais otimistas. Por este motivo, o Estado atuaria como uma espécie de empregador de última instância, contratando de acordo com a sua necessidade, mantendo o nível de emprego. Do contrário, um dos seus efeitos adversos poderia ser também o de ter um efeito inflacionário na economia, fator este que não é considerado como desejável. Neste caso, o programa tem um caráter permanente em vista de não produzir expectativas inflacionárias mais elevada no curto prazo.

Por este motivo, a questão da estabilidade do sistema financeiro não pode se dissociar da luta pelo pleno emprego da economia, ou seja, transforma-se em um problema de como criar oportunidades de trabalho para todos. ${ }^{33}$ Dentro deste referencial teórico, essa política também poderia representar uma alternativa viável para criar um cenário de suavizar a construção da fragilidade do sistema financeiro no tempo, pois, na medida em que a economia se direciona ao nível de pleno emprego, o nível do gasto autônomo será o máximo possível, consequentemente, toda renda gerada constituirá em funding para os capitalistas via lucros retidos, assim, estes conseguiriam honrar as suas obrigações financeiras, além de diminuir as suas necessidades de endividamento por meio do financiamento externo.

Porém, conforme explicita Keynes (1936 [1983]), a situação de pleno emprego é um caso fortuito se deixado apenas pelas forças de mercado, por isso é necessário a atuação ativa do governo em momentos de uma crise sistêmica e de forma anticíclica. Ademais, no plano teórico, este é o único cenário específico possível em que se poderia afirmar que se alcançaria os resultados da Lei de Say, isto é, que "toda renda (salários e lucros) é inteiramente compra de mercadoria de bens e serviços e, portanto, não pode haver um excesso de produção ou renda em relação à demanda ou às despesas efetivamente realizadas" (Miglioli, 1987, p. 11). Portanto, neste cenário, não existiria um espaço teórico para ocorrência de uma crise financeira. Esse

\footnotetext{
${ }^{33}$ Por isso, utilizar-se somente das políticas do Big Bank e Big Government não é suficiente para garantir um cenário de estabilidade financeira. Nas suas palavras: "[t]he special instability of recent years, in which the economy oscillates between prospective runaway inflation and incipient debt deflation, is a side effect of the methods to avoid a debt deflation and deep depression" (Minsky, 1986, p. 45).
} 
cenário determinará, por definição, uma estruturação hedge para todo o sistema econômico no longo prazo. Percebe-se que neste cenário, uma política de sustentação da demanda agregada e submetido a um programa de emprego universal poderia oferecer um mecanismo importante para suavizar o ciclo econômico e os impactos decorrentes de um processo minskyano de fragilização financeira.

\section{Considerações finais}

presente artigo realizou uma discussão crítica acerca dos pressupostos teóricos que embasam a chamada política macroprudencial, tendo como referência a perspectiva pós-Keynesiana. Desde o princípio, buscou-se demonstrar que as causas para as crises financeiras nesta visão parte do pressuposto diferentes daqueles elencados pela teoria macroeconômica ortodoxa. É evidente que uma teoria no qual os bancos possuem um papel de serem meros intermediários financeiros e as crises são sempre resultados de falhas de mercado ou de choques exógenos, não é capaz de compreender a natureza da instabilidade financeira, nem tampouco como esta é gerada no tempo.

Portanto, necessitam-se de propostas econômicas alternativas que admitam que a instabilidade representa a essência do próprio funcionamento do capitalismo moderno no qual o ciclo econômico é inerentemente instável e normal em relação ao sistema financeiro. Isso acontece porque a decisão de investimento pelas firmas apresenta um caráter cíclico no tempo. Nesta visão, o papel da moeda é se constituir no ativo mais líquido em uma economia capitalista inserida em um ambiente de incerteza fundamental, possuindo a função de excelência em liquidar obrigações financeiras em momentos de expectativas mais pessimistas. Desta forma, flutuações na sua demanda pelos agentes econômicos possuem efeitos sobre a economia real.

Além disso, é preciso compreender que a introdução de inovações pelo sistema financeiro muda as condições de financiamento da economia gerando resultados schumpeterianos sobre o desenvolvimento do capitalismo. De modo que a regulação, em si mesma, pode ser também desestabilizadora, capaz de validar a funcionalidade dessas inovações em oferecer novas oportunidades de lucro. Logo, é evidente que a regulação precisa considerar o caráter dinâmico em relação ao papel ativo das finanças sobre a dinâmica econômica. Ainda, é preciso reconhecer que a atividade bancária e suas decisões de investimento por estarem inseridas em um ambiente de incerteza fundamental, no qual teoricamente somente existem perspectivas de realização de seus lucros futuros, as instituições financeiras estarão sempre sujeitas a potencialmente sofrerem uma crise de insolvência, ou seja, independentemente dos requerimentos que forem estabelecidos pelos reguladores 
macroprudenciais.

Um caminho alternativo que vai além da regulação bancária, que foi proposto neste artigo, seria que para promover um mecanismo de suavizar o ciclo financeiro que implicaria em criar um cenário para estabilização das próprias fontes de lucratividade do sistema bancário, que em última instância, pode ser representada pela demanda agregada da economia. Em especial, salienta-se a necessidade de promover uma meta de atingir uma posição de pleno emprego. Por este motivo, deve-se tomar como proposta de política econômica a implementação de forma conjunta do chamado Big Bank, Big Government e, principalmente, do Big Employment, isto é, sendo que a efetividade dessas políticas precisa prescindir uma em relação a outra para que se possa ser alcançada o desejado processo de estabilização financeira das economias capitalista modernas no longo prazo.

\section{Referências}

Arestis, P. (2009) "New Consensus Macroeconomics: a critical appraisal" Levy Economics Institute Working Paper, n. 564, 25p.

Avdjiev, S.; Koch, C.; McGuire, P. and Peter, G. V. (2016) "International prudential spillovers: a global perspective" BIS Working Paper, n. 589, 22p.

Bank of England (2009) "The role of macroprudential policy" London: Bank of England, Discussion Paper, 37p.

Bank of England (2011) "Instruments of macroprudential policy" London: Bank of England, Discussion Paper, 41 p.

Bastos, R. B. (2013) "Uma política macroprudencial para estabilidade financeira" Lisboa: Banco de Portugal, Relatório de Estabilidade Financeira, p.77-92.

Basel Committee on Banking Supervision (BCBS) (2010). "Basel III: A Global Regulatory Framework for More Resilient Banks and Banking Systems" A Consultative Document, 68p.

Bernanke, B.S.; Gertler, M. and Gilchrist, S. (1999) "the financial accelerator in a quantitative business cycle framework" In: Taylor, J. and Woodford, M. (eds.) Handbook of Macroeconomics, v. 3, p. 1341-1393.

Blanchard, O.; Dell'Ariccia, G. and Mauro, P. (2010) "Rethinking Macroeconomic Policy" Washington DC: International Monetary Fund, IMF Staff Position Note SPN 10/03, 18p.

Blanchard, O. and Summers, L. H. (2017) "Rethinking stabilization policy: evolution or revolution?" NBER Working papers, n. 24179, 45p. 
Borio, C. (2003) "Towards a macroprudential framework for financial supervision and regulation?" BIS Working Paper, n.128, 22p.

Borio, C. (2010) "Implementing a macroprudential framework: blending boldness and realism" Basel: Bank for International Settlements (BIS). Disponível em: http://www.bis.org/repofficepubl/hkimr201007.12c.pdf. Acesso em: Dez/2018.

Borio, C. (2016) "Revisiting three intellectual pillars of monetary policy" Cato Journal, 36(2), p. 213-238.

Borio, C.; Furfine C. and Lowe, P. (2001) "Procyclicality of the financial system and financial stability: issues and policy options" Basel: Bank for International Settlements, BIS Working Papers, n. 1, 57p.

Carvalho, F. A. and Castro, M. R. (2015) "Macroprudential and monetary policy interaction: a Brazilian perspective" BCB Working Paper series, n. 405, 51 p.

Carvalho, J. F. C. (2016) "On the nature and role of financial system in Keynes's entrepreneurial economies" Journal of Post Keynesian Economics, 36(3), p. 287-307. Doi: https://doi.org/10.1080/01603477.2016.1190282

Cesaratto, S. (2016) "The state spends first: logic, facts, fictions, open questions" Journal of Post Keynesian Economics, 39(1), p. 44-71. Doi: https://doi.org/10.180/01603477.2016.1144733

Clement, P. (2010) "The term "macroprudential": origins and evolutions", BIS Quarterly Review, p. 59-67.

Davidson (1982) "Rational expectations: a fallacious foundation for studying crucial decision-making process" Journal of Post Keynesian Economics, 5(2), p. 182198.

Diamond, D. W. and Dybvig, P. (1983) "Bank runs, deposit insurance and liquidity" Journal of Political Economy, 95(5), p. 401-419.

Fama, E. (1980) "Banking in the theory of finance" Journal of Monetary Economics, 6, p. 39-57.

Galati G. and Mosneer, R. (2011) "Macroprudential policy - a literature review", BIS Working Paper, n. 337, 38p.

Gurley, J.G. and Shaw, E.S. (1955) "Financial aspects of financial development" American Economic Review, 45(4), p. 515-538.

Guttmann, R. (2008) “Uma introdução ao capitalismo dirigido pelas finanças” Novos Estudos, 82, p. 11-33. Doi: https://doi.org/10.1590/S010133002008000300001 
International Monetary Fund (FMI) (2011) "Macroprudential policy: an organizing framework" Washington DC: International Monetary Fund. Disponível em: https://www.imf.org/external/np/pp/eng/2011/031411.pdf_Acesso em: Dez/2018.

International Monetary Fund.; Basel Committee on Banking Supervision (BCBS) and Bank for International Settlements (BIS) (2016) "Elements of effective macroprudential policies: lessons from International Experience". Washington DC: International Monetary Fund. Disponível em: https://www.imf.org/external/np/g20/pdf/2016/083116.pdf__Acesso em: Dez/2018.

Jordà, Ò.; Singh, S. and Taylor, A. (2020) "The long-run effects of monetary policy" NBER Working Paper Series n. 26666, 35p.

Kalecki, M. (1954 [1977]) Teoria da Dinâmica Econômica: Ensaio sobre as Mudanças Cíclicas e a Longo Prazo da Economia Capitalista. Série Os Economistas, São Paulo: Editora Nova Cultural.

Keynes, J. M. (1983 [1936]). A Teoria Geral do Emprego, dos Juros e da Moeda. São Paulo: Abril Cultural.

Keynes, J. M. (1937a) "Alternatives theory of the rate of interest" The Economic Journal, 47(186), p. 241-252.

Keynes, J. M. (1937b) "The 'ex-ante' theory of the rate of interest" The Economic Journal, 47(188), p. 663-669.

Kindleberger, C. P. and Aliber, R. (1978 [2005]), Manias, Panics and Crashes: A history of Financial Crises. New Jersey: Willy and Sons, Inc., $5^{\text {th }}$ edition.

Kregel, J. (1997) "Margins of safety and weight of the argument in generating financial fragility" Journal of Economic Issues, 31(2), p. 543-548.

Kregel, J. (2014) "Minsky and dynamic macroprudential regulation" Levy Economics Institute Public Policy Brief, n. 131, 16p.

Lee, M.; Gaspar, R. and Villaruel, M. L. (2017) "Macroprudential policy in developing Asian countries" ADB Economics Working Paper series, n. 510, 38p.

Lerner, A. (1943), "Functional finance and the federal debt", Social Research, 10, p. 38-51.

Levine (1997) "Financial development and economic growth: views and agenda" Journal of Economic Literature, XXXXV, p. 688-726.

Lowe, P. (2002) "Credit risk measurement and procyclicality" BIS Working papers. $\mathrm{n}$. $16,18 \mathrm{p}$. 
Mehrling, P. (1999) "The vision of Hyman P. Minsky" Journal of Economic Behavior \& Organization, v. 39, p. 129-158. Doi: https://doi.org/10.1016/S01672681(99)00029-3

Miglioli, J. (1987) Acumulação de Capital e demanda efetiva São Paulo: Editora Taq.

Minsky, H. P. (1982 [2016]) Can it Happen Again? Essays on Instability and Finance. New York: Routledge Classics.

Minsky. H. P. (1985) "The legacy of Keynes” Hyman P. Minsky Archive, paper n. 26. Disponível em: http://digitalcommons.bard.edu/hm_archive/26_Acesso em: Dez/2018.

Minsky. H. P. (1986 [2008]) Stabilizing an Unstable Economy. New York: McGrawHill.

Minsky, H. P. (1988), "Schumpeter: finance and evolution" Hyman P. Minsky Archive, paper n. 314. Disponível em: http://digitalcommons.bard.edu/hm_archive/314_Acesso em: Dez/2018.

Minsky, H. P. (1992) "The financial instability hypothesis" Levy Economics Institute Working Paper, n. 74, 10p.

Modigliani, F. and Miller, M. H. (1958) "The cost of capital, corporation finance and the theory of investment" American Economic Review, 51, p. 95-116.

Oliveira, M.; Luporini, V., Licha, A. (2018) "Macroprudential policy debate, concepts and the Brazilian context" Brazilian Keynesian Review, 4(1), p. 35-61. Doi: https://doi.org/10.33834/bkr.v4i1.113

Paula, L. F. R. (2014) Sistema financeiro, bancos e financiamento da economia: uma abordagem pós-Keynesiana. 1ed., Rio de Janeiro: Elsevier.

Papadimitrou e Wray (1999) "Minsky's analysis of financial capitalism" Levy Economics Institute Working Papern. 275, 15p.

Possas, M. L. (1999) "Demanda efetiva, investimento e dinâmica: a atualidade de Kalecki para a teoria macroeconômica" Revista de Economia Contemporânea, 3(2), p. 17-46.

Quint, D. and Rabanal, P. (2013) "Monetary and Macroprudential policy in an estimated DSGE model of the euro area" IMF Working Papers n. 209, 59.

Romer, P. (2016). "The trouble with macroeconomics". The Common Memorial Lecture of the Omicron Delta Epsilon Society. Disponivel em: https://paulromer.net/wp-content/uploads/2016/09/WP-Trouble.pdf Acesso em: Dez/2018. 
Shin, H. S. (2013). "Adapting macro prudential approaches to emerging and developing economies". In: Canuto, O. Cavallari, M. (eds.) Dealing with the Challenges of Macro Financial Linkages in Emerging Markets, World Bank, p. $17-55$

Stiglitz, J. (2010) "The financial crisis of 2007-2008 and its macroeconomic consequences" In: Griffith-Jones, S., Ocampo, J. A., Stiglitz, J. (eds.) Time for a Visible Hand - Lessons from the 2008 World Financial Crisis. Oxford: Oxford University Press, p. 19-49.

Stiglitz, J. and Weiss, A. (1981) "Credit Rationing in Markets with Imperfect Information." American Economic Review, 71(3), p. 393-410.

Tcherneva, P. R. (2018) "The Job Guarantee: design, job and implementation" Levy Economics Institute Working Paper, n. 902, 66p.

Vasconcelos, D. S. (2014) "Minsky on Big Government" Brazilian Journal of Political Economy, 34, p. 15-38. Doi: https://doi.org/10.1590/S010131572014000100002

Vergnhanini, R. and Conti, B. (2017) "Modern Money Theory: a criticism from the periphery" Brazilian Keynesian Review, 3(2), p. 16-31. Doi: https://doi.org/10.33834/bkr.v3i2.115

Wray, L. R. (1998) Understanding Modern Money: a key to full employment and price stability. Cheltenham: Edward Elgar.

Wray, L. R. and Tymoigne, E. (2008) "Macroeconomics meets Hyman P. Minsky: The financial Theory of Investment" Levy Economics Institute Working Paper, n. 543, 23p. 